\title{
APRESENTANDO CESARE RUFFATO
}

em tradução de Mariarosaria Fabris*

Médico e docente de Radiologia e Radiobiologia, Cesare Ruffato nasceu em San Michele delle Badesse (Pádua - Itália), em 1924. Estreou como poeta em 1960, com Tempo senza Nome. A esse primeiro livro, seguiram-se numerosas publicações em italiano e em vêneto, até as recentes Etica Declive (1996), Scribendi Licentia (1998), Saccade (1999) e Sinopsie (2002). Suas composições foram traduzidas em várias linguas, inclusive em português. Poesie scelte/Poesias escolhidas (1997) apresenta uma seleção de suas obras ao público lusófono. Outras traduções de suas poesias em português foram publicadas em Cult-Revista Brasileira de Literatura, em Cadernos de Literatura em Tradução e em Itinerários-Revista de Literatura. Cesare Ruffato é também tradutor: verteu do latim para o italiano o Liber Medicinalis, de Quintus Serenus Sammonicus, e, atualmente, está se dedicando à tradução em italiano de poesias de Sá de Miranda.

\section{FANTASIA DELL'ANIMA**}

\section{I}

Il cieco lascia andare raffinati impulsi, il cane fedele tira via giusto nella città di mare con fanciulle di saliva dolce

\section{FANTASIA DA ALMA}

O cego deixa escapar refinados impulsos, o cão fiel se arranca justo na cidade à beira-mar com moças de saliva doce

(*) Professora aposentada do Departamento de Letras Modernas da FFLCH-USP.

${ }^{(* *)}$ As oito poesias de Cesare Ruffato, traduzidas para este número de Língua e Literatura, fazem parte do volume Saccade, publicado em dezembro de 1999. Para a tradução aqui apresentada, no entanto, preferiu-se trabalhar com a primeira versão dessas composições, que permanece inédita. 
e guizzi luciferini. Il risveglio scoppia vuoti e luci incoerenti.

I cent'occhi interni anche nel sonno addestrano i limiti del pensiero

a sfiorare mondo discosto

e privato

insieme, spettro inesorabile nero dei più dilatati accenti.

II

Già nell'infanzia gli avamposti avvitano

tentoni curiosi sospetti e feticci

al senso lato dell'oscurità.

L'incessante avventura suona una triste

iperestesia fra gli alberi di paesaggio

rovesciato una galleria di posizioni del corpo. Ogni parte dell'essere fende senza spruzzi i liquamina della vita la fantasia intensa dell'anima.

III

Rincorre le curve paterne nei barlumi

di coni e bastoncelli bene gli viene lo sguardo muto oltre il cielo e il mare una festa d'altra era e sostanza. Ciò che non ha avuto o ha smarrito pertiene al regno delle luci ed è solo dei vedenti con le pietre preziose dell'anima. e lampejos luciferinos. O despertar explode vácuos e luzes incoerentes. Cem olhos internos mesmo no sono treinam os limites do pensamento para roçar mundo à parte e ao mesmo tempo próprio, espectro inexorável, negro dos mais dilatados acentos.

Já na infância postos avançados atarraxam

às cegas curiosas suspeitas e fetiches

ao sentido lato da escuridão.

A incessante aventura toca uma triste

hiperestesia entre árvores de paisagem virada, uma galeria de posições do corpo. Cada parte do ser fende sem respingos os liquâmenes da vida a fantasia intensa da alma.

Persegue as curvas paternas nos vislumbres

de cones e bastonestes, lhe convém o olhar mudo além do céu e o mar uma festa de outra era e substância. O que não teve ou perdeu pertence ao reino das luzes e só é dado aos videntes com as pedras preciosas da alma. 
IV

In primavera l'orologio della mente scintilla verso il sole labirinto di impercettibili gemme il bimbo d'avorio nel letto materno la malinconia del sembiante negato il ritmo scombinato dell'acqua invisibile, estraneo agli istinti dell'attuale società lunga fila di bocche e membra dai sogni superbi tutta nervi scoperti e paludamenti narcisi.

\section{V}

Nella maschera pruriginosa dell'estate

equilibra con radar in mito gli indizi singolari gli idoli delle riconfigurazioni i passi più bui.

La retina memoriale misura differenze

eccellenti organizza la bussola acustica, l'enigma dell'intorno affettivo, il pensiero immaginato. In gesti retorici congela l'idea dell'inverno glabro sovente si sente nuda preda.

VI

Nel silenzio ottico abbacinante può intuire tratti felpati dell'orizzonte

lo sguardo patetico della lente universale

può muovere con specillo rabdomante
Na primavera o relógio da mente cintila para o sol labirinto de imperceptiveis gemas a criança de marfim no leito materno a melancolia do semblante negado o ritmo desencontrado da água invisivel, estranho aos instintos da atual sociedade, longa fila de bocas e membros de sonhos soberbos toda nervos expostos $\mathrm{E}$ ornamentos narcíseos.

Na máscara pruriginosa do verão equilibra de radar em mito os indícios singulares, os ídolos das reconfigurações, os passos mais obscuros.

A retina memorial mensura diferenças excelentes, organiza a bússola acústica, o enigma do entorno afetivo, o pensamento imaginado. Em gestos retóricos congela a idéia do inverno glabro, a miúdo se sente desnuda presa.

No silêncio óptico ofuscante pode intuir traços felpudos do horizonte

o olhar patético da lente universal

pode mover com tenta rabdomante 
la storia di reliquie pietre papille intatte che sanno più di quanto il volto traduca un mondo di nuova antropologia.

VII

Il viaggio stereotipo dal giardino al campo alla selva di stelle trabocca scale musicali fantastica le mani saccadiche ad altre forme di privilegiata autonomia che reinventa sempre straniata geografia e più amabile il plastico familiare.

VIII

La monotona risonanza striscia i passi spaziati i tacchi più alti

i polpastrelli leggono i prodigi

della natura in forme agenti e pazienti

inattese, la riva rimbalza nell'acqua

parole indovinate.

Concentro emulazione

onde note con più suono

perfeziono la scena sospesa. a história de relíquias pedras papilas intactas que sabem mais do que o rosto traduz de um mundo de nova antropologia.

A viagem estereótipo do jardim ao campo, à selva de estrelas trasborda escalas musicais fantasia mãos sobressaltadas e outras formas de privilegiada autonomia que reinventa sempre estranha geografia e mais amável o molde familiar.

A monótona ressonância raspa nos passos espaçados, nos saltos mais altos

as pontas dos dedos lêem os prodígios

da natureza em formas agentes e pacientes inesperadas, a orla resvala na água

palavras adivinhadas.

Concentro emulação com notas de mais som aperfeiçôo a cena suspensa. 